plate, rod, delay and variable refractive index lenses was shown. One exhibit showed a large metal-plate lens of $8 \mathrm{ft}$. aperture and focal length $11 \mathrm{ft} .8 \mathrm{in}$. operating on a wave-length of $10.7 \mathrm{~cm}$. The horn feed for this lens was traversed to and fro across the focal plane, and monitor receiver aerials indicated that the beam scanned over $\pm 18^{\circ}$ with a loss of less than 2 decibels at the extremities of the scan. A further exhibit in this section showed apparatus for the automatic recording of phase and amplitude distribution in the wave-front across the aperture plane of experimental lenses.

General Research Items. A number of research items, the results of which aim at producing radar sets giving better performance, was shown. These items covered a wide field and included work on the magnetic clutch principle initiated at the National Bureau of Standards in the United States. The clutch relies for its action on the fact that a 'sludge' of fairly low viscosity, produced by immersing iron filings in oil, solidifies when subjected to a magnetic field. This work aims at producing improved servo-motor drives. Another interesting exhibit demonstrated the production of a standard milliwatt of power on a wave-length of $10 \mathrm{~cm}$. for the calibration of radar receivers, while new techniques and developments in radar test gear and electro-chemistry were also shown.

Workshop Exhibits. Essential to the success of modern research workers is the co-operation of firstclass workshops. The dozen or so exhibits in the workshops of the Establishment indicated just how well its scientific workers are served in this respect. A fine collection of modern machine tools was shown with examples of turning, milling, grinding, moulding and plating. Examples of completed work included a large centrifuge capable of subjecting weights of $150 \mathrm{lb}$. to $200 \mathrm{~g}$.

A film entitled "Debellamus Superbos", describing the work of the Establishment from the earliest sound-locating equipment to the present-day radar, was shown each day during the exhibition.

F. E. JONES

1346

\section{ASSOCIATION OF SPECIAL LIBRARIES AND INFORMATION BUREAUX}

\section{ANNUAL CONFERENCE}

$\mathrm{T}$ HE twenty-forth annual conference of the Association o Special Libraries and Information Bureaux, the fint to be held since the amalgamation of the Assod atiol with the British Society for Internationd Billiography, presented comparatively few features of interest to scientific workers generally. Although rather more than two hundred were present at Ashorne Hill, Leamington Spa, during the weekend September 9-12, and the attendance represented a wide range of interests, the Conference in some ways did not quite provide the opportunity for discussion of the Association's own affairs that was usually given by the annual general meeting, nor was the gap filled by Dr. Percy Dunsheath's reference to the early history of the Association at the outset of his presidential address on the Saturday morning.
The main features of Dr. Dunsheath's address wëre his references to the inadequacy of present-day facilities for reference libraries in science and technology and to the need for establishing higher standards of training and qualification for the stafis employed in scientific and technological libraries. Both these matters, he considered, call for strong action, and he maintained that the present reference library facilities in science and technology are a disgrace to Great Britain. An intensively indus. trialized country like Britain is particularly dependent on the ready dissemination of existing knowledge among scientific men and technologists; yet stocks of books are not readily available on account of lack of space, grants for new books are falling more and more into arrears and the flood of new knowledge is increasingly beyond the capacity of the under-paid, under-staffed and under-equipped librarian. Dr. Dunsheath said that the Patent Office Library is the most useful technical library in London and the best for its purpose in the United Kingdom, but he complained that it is now closed at 6 p.m. instead of at 10 p.m., while delays in binding, the absence of books from open shelves and the inadequacy of staffmainly due to a cut in the budget-seriously hinder its usefulness. Much the same criticism could be made of the Science Museum Library at South Kensington, and Dr. Dunsheath urged that provision of a new Library of Science and Technology in the centre of London, conceived on a grand scale, and using the practical experience and tradition of the Patent Office Library, would be the best contribution which the Government could make to our prosperity at the present time.

Following Dr. Dunsheath's address at a session on business archives, papers were given by Mr. F. G. Emmison, county archivist, Essex Record Office, and Mr. E. C. Baker, librarian and archivist of the Post Office, which were designed to assist members in selecting papers for retention, and which also discussed such archives as sources of history of business or industrial enterprises. Three papers presented at the afternoon session, which described the starting and operation of three new libraries, should be of particular interest to those who may be concerned with the formation and management of new research libraries or information centres. In one of those the library of the Institute of the Motor Industry was described by its librarian, Mr. C. E. C. Hewetson. Miss M. Gossett described the formation and operation of the library of the Atomic Energy Research Establishment at Harwell, and Mr. E. Ower, intelligence officer to the British Shipbuilding Research Association, the library of that Association.

The third session of the Conference, on Sunday morning, was concerned with the extraction of commercial and technical information from correspond. ence files, and the two papers presented by Mr. D. V. Arnold and Miss E. W. Parker considered both the most suitable techniques and the problem of ultimate storage. The fourth session, on Sunday afternoon, discussed the problems of obtaining official publications of interest, but centred essentially around those issued by H.M. Stationery Office, the director of which, Mr. W. Cox, contributed one of the three papers. The contents and arrangement of the daily, monthly and annual lists or catalogues issued by H.M. Stationery Office received some comment, while Miss Barbara Kyle dealt with problems presented by the United Nations Organisation's documents. 